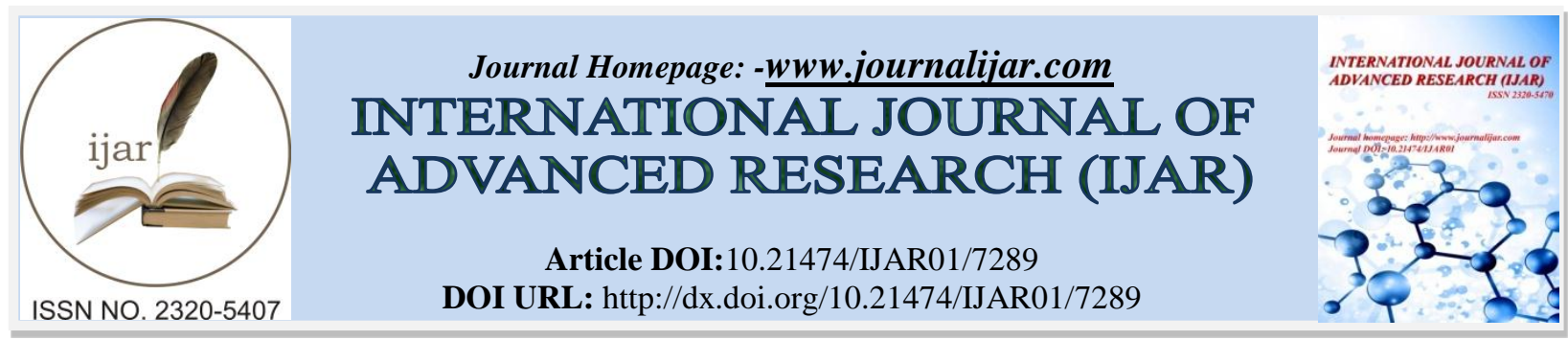

RESEARCH ARTICLE

\title{
CORRELATION BETWEEN GRACE RISK SCORE AND CARDIOVASCULAR EVENT RATE IN PATIENTS WITH ST SEGMENT ELEVATION MYOCARDIAL INFARCTION WITH SUCCESSFUL FIBRINOLYSIS AND DELAYED CORONARY INTERVENTION.
}

\author{
Ahmed H. Elesily ${ }^{1}$, Mohammed A.Mandour ${ }^{2}$, Mahmoud A. Hashish ${ }^{3}$, Mohy M. Samy ${ }^{4}$ and Mohammed S. \\ Elbaz ${ }^{5}$. \\ 1. Cardiology Resident . \\ 2. Lecturer of Cardiology - Faculty of Medicine - Al-Azhar University. \\ 3. Assistant Professor of Clinical Pathology - Faculty of Medicine - Al-Azhar University. \\ 4. Assistant Professor of Cardiology -Faculty of Medicine - Al-Azhar University. \\ 5. Professor of Cardiology - Faculty of Medicine - Al-Azhar University.
}

\section{Manuscript Info}

Manuscript History

Received: 15 April 2018

Final Accepted: 17 May 2018

Published: June 2018

\section{Keywords:-}

myocardial injury, GRACE score, successful fibrinolysis, complications, acute ST segment elevation myocardial infarction, follow up.

\section{Abstract}

Background: In several countries, Fibrinolytic therapy represents the main reperfusion therapy for most STEMI patients due to limitation of PCI-capable hospitals. Current practice guidelines recommended routine early pharmacoinvasive (within 2-24 h) after successful fibrinolysis, however, it cannot be performed in timely fashion due to limitation of PCI-capable hospitals.

Aim of the work: to evaluate the prognostic utility of the GRACE risk score in patients receiving delayed intervention after successful fibrinolysis in non PCI-capable hospitals.

Methods: This was a prospective cross sectional observation study that was conducted from March 2017 to February 2018 and included 120 patients presented to the coronary care unit at AL-Azhar University Hospital and Al Mataryia Teaching Hospital with acute STEMI and treated successfully with thrombolytic therapy. All patients were subjected to complete clinical assessment, serial ECGs, Echocardiography, full labs. The STEMI patients who had successfully fibrinolysis and received delayed PCI (during 24h to 14 days) were included. Follow up was done on outpatient basis monthly after delayed PCI for three months.

Results: There were 70 patients $(58.3 \%)$ with low GRACE score and 50 patients $(41.7 \%)$ with high GRACE score. This study shows that more than three quarters of the studied cases had no follow up complications and the most frequent complication was ACS. The percentage of cases which had ACS was $13.3 \%$ (number of patients 16), the percentage of cases with HF was $9.2 \%$ ( number of patients 11 ), the percentage of cases with stroke was $1.7 \%$ ( 2 patients ) and only one case died. During 3 months, the cardiovascular complications occurred in 8 patients in low GRACE group and 20 patients in high GRACE group $(\mathrm{P}<0.001)$. Cases with cardiovascular complications had significantly higher time from successful fibrinolysis to PCI (P $<0.001)$. 
Conclusion: The long delay pharmacoinvasive strategy in intermediate to high GRACE score after successful fibrinolysis in non PCI-capable facilities was associated with worse cardiovascular outcomes (death, re hospitalized with ACS, re-hospitalized with HF and stroke) than the patients with low GRACE score within 3 months.

Copy Right, IJAR, 2018,. All rights reserved.

\section{Introduction:-}

Primary percutaneous coronary intervention (PPCI) is preferred reperfusion therapy for acute ST-elevation myocardial infarction (STEMI). However, the PCI-capable center is still limited in several countries including Egypt.

Therefore, fibrinolytic therapy is the main reperfusion therapy for most STEMI patients in Egypt [1]. Even more, early pharmacoinvasive (within 2-24 h after successful fibrinolysis) cannot be performed in a timely fashion due to limitation of PCI-capable hospitals. Therefore, risk stratification is a crucial issue in planning management in nonPCI capable hospitals. Patients with intermediate to high risk for adverse cardiovascular event should be transferred for coronary angiogram as soon as possible [2].

Although several risk scores for acute coronary syndrome (ACS) have been developed for stratified risk of ACS patients, GRACE (Global Registry of Acute Coronary Events) score is developed to focus on clinical risk assessment and to improve the selection of patients for clinical and interventional procedures following an ACS episode [3].

Many studies and meta-analysis demonstrated the accuracy and the usefulness of the GRACE score on the mortality of ACS patients in hospital and follow-up after hospital discharged [4].

\section{Patients and Methods:-}

This prospective observational study involved 120 patients from the attendants of the emergency department at ALAzhar University Hospital and Al Matarya teaching hospital (MTH) who admitted with the diagnosis of ST elevation myocardial infarction (STEMI) and received streptokinase 1.5 MU as per the institutional protocol, during the period from August 2016 to April 2017.

Patients were observed in the intensive coronary care unit for at least five days. All patients presented, within 6 hours from symptom onset with ECG show ST-segment elevation at the J point, in at least 2 contiguous leads, $\geq 2$ $\mathrm{mm}(0.2 \mathrm{mV})$ in men $\geq 40$ years, $2.5 \mathrm{~mm}(0.25 \mathrm{mV})$ in men $<40$ years or $\geq 1.5 \mathrm{~mm}(0.15 \mathrm{mV})$ in women in leads $\mathrm{V} 2-\mathrm{V} 3 \mathrm{and} /$ or $\geq 1 \mathrm{~mm}(0.1 \mathrm{mV})$ in other contiguous chest leads or the limb leads [8].

Exclusion criteria were patients with unsuccessful fibrinolysis (ST-segment decrease in elevation less than $50 \%$ at $90 \mathrm{~min}$ after fibrinolysis), those receiving early coronary intervention ( $<24 \mathrm{~h}$ after fibrinolysis).

Also, Patients receiving very delayed coronary intervention (two weeks after fibrinolytic therapy)and those who denied for further interventions after Fibrinolysis.

Patients received primary PCI or rescue PCI were excluded.

Also, Patients with previous history of coronary-artery bypass surgery were excluded. The study protocol was approved by Al-Azhar University, Faculty of Medicine. A chart review was performed, and data were collected including patient demographics, medical history, examination, laboratory tests, ECG, echocardiography.

History was taken including age, gender, smoking was recognized as a lifetime history of $>100$ cigarettes in their entire life and had continued smoking in the last 6 months was considered a positive smoking history, while exsmokers were defined having history of smoking at least 100 cigarettes in their entire life and had completely stopped smoking for at least 6 months [5], Current diabetes mellitus was recognized as having history of DM on admission with the use of oral anti-hyperglycemic full agents or any extended release insulin and confirmed by laboratory HbA1c on admission if more than 6.5\% [6], dyslipidemia was defined by total cholesterol $\geq 220 \mathrm{mg} / \mathrm{dl}$, 
triglyceride $\geq 150 \mathrm{mg} / \mathrm{dl}$, high-density lipoprotein (HDL cholesterol) $\leq 40 \mathrm{mg} / \mathrm{dl}$ or current use of antihyperlipdemic drug [7], hypertension was defined as systolic/diastolic blood pressure $\geq 140 / 90 \mathrm{mmHg}$ or patients having history of hypertension and current use of any antihypertensive medications [8], Family history of premature coronary artery disease was defined as fatal or non-fatal events in first degree relatives men $<55$ or women $<60$ years [9].

Full clinical examination was done including vital signs, cardiac examination to assess the Killip classification for each patient. Heart failure included advanced congestive heart failure (New York Heart Association functional class III/IV) or acute heart failure (Killip class II-IV).

Twelve leads ECG was obtained to confirm the diagnosis. M-mode, two-dimensional echocardiography and doppler examination was performed for all patients in the left decubitus position during normal respiration using a GE Vivid 5 Ultrasound Machine (Echo Pac; GE Vingmed, Horten, Norway) according to the recommendations of American Society of Echocardiography to detect left ventricle size, left atrium size, left ventricular ejection fraction, any wall motion abnormalities or ischemic complications and to detect any morbidities during the in hospital follow up.

Laboratory tests were done including routine labs that include liver and kidney functions. Serum cardiac markers that include Serial measurement of cardiac troponin I (CTnI), myocardial band of creatine kinase (CK-MB) and creatine kinase (CK). Measured hormones and their respective reference values are: CK (up to 195 U/L), CK-MB (up to $25 \mathrm{U} / \mathrm{L})$, Troponin I $(0-0.1 \mathrm{ng} / \mathrm{ml})$.

The STEMI patients who had successfully fibrinolysis and received delayed PCI (during $24 \mathrm{~h}$ to 14 days) were included. Follow up was done within the clinic every 21 days after delayed PCI for three months. The primary end point for this study was the composite outcomes, which included all-cause mortality, re-hospitalization with acute coronary syndrome (ACS), re-hospitalization with heart failure (HF) and stroke at 1 and 3-month.

Re-hospitalized with ACS is defined as re-admission after discharge from hospital with ACS composed with clinical chest pain, rising of cardiac enzymes and dynamic ST-segment change.

Re-hospitalized with heart failure is defined as readmission after discharge from hospital with clinical ecompensated heart failure or received intravenous diuretic.

\begin{tabular}{|c|c|c|c|}
\hline \multicolumn{2}{|c|}{ Variables } & Mean \pm SD & Range \\
\hline \multicolumn{2}{|c|}{ Onset (hours) } & $5.1 \pm 2.1$ & $1.0-12.0$ \\
\hline \multicolumn{2}{|c|}{ HR (Beat/minute) } & $97.9 \pm 21.7$ & $40.0-150.0$ \\
\hline \multicolumn{2}{|c|}{$\mathrm{SBP}(\mathrm{mmHg})$} & $126.6 \pm 28.5$ & $80.0-190.0$ \\
\hline \multicolumn{2}{|c|}{$\mathrm{DBP}(\mathrm{mmHg})$} & $77.2 \pm 17.7$ & $50.0-120.0$ \\
\hline \multicolumn{2}{|c|}{ Serum creatinine $(\mathrm{mg} / \mathrm{dl})$} & $1.23 \pm 0.51$ & $0.40-2.30$ \\
\hline \multicolumn{2}{|c|}{ Serum urea $(\mathrm{mg} / \mathrm{dl})$} & $38.0 \pm 11.9$ & $20.0-80.0$ \\
\hline \multicolumn{2}{|c|}{$\mathrm{Hb}(\mathrm{gm} / \mathrm{dl})$} & $13.6 \pm 1.4$ & $10.0-16.0$ \\
\hline \multirow{2}{*}{\multicolumn{2}{|c|}{$\frac{\mathrm{RBS}(\mathrm{mg} / \mathrm{dl})}{\mathrm{EF} \%}$}} & $284.7 \pm 97.6$ & $100.0-500.0$ \\
\hline & & $51.7 \pm 8.1$ & $30.0-68.0$ \\
\hline \multicolumn{2}{|c|}{$\mathrm{EF} \%$} & $\mathrm{~N}$ & $\%$ \\
\hline \multirow[t]{3}{*}{ Killip Class } & $\mathrm{I}$ & 87 & 72.5 \\
\hline & II & 28 & 23.3 \\
\hline & III & 5 & 4.2 \\
\hline \multicolumn{2}{|c|}{ DKA } & 9 & 7.5 \\
\hline \multicolumn{2}{|c|}{ Crepitaion } & 67 & 55.8 \\
\hline \multicolumn{2}{|c|}{ Tachyarythmia } & 21 & 17.5 \\
\hline \multicolumn{2}{|c|}{ Bradyarrythmia } & 10 & 8.3 \\
\hline \multicolumn{2}{|c|}{ Cradiac Arrest } & 11 & 10.8 \\
\hline \multirow[t]{3}{*}{ Site (ECG) } & Anterior & 69 & 57.5 \\
\hline & Inferior & 46 & 38.3 \\
\hline & Both & 5 & 4.2 \\
\hline
\end{tabular}

Table 1:-Clinical condition and laboratory findings of the studied cases at presentation 
All patients received a loading dose of $300 \mathrm{mg}$ of clopidogrel in combination with $300 \mathrm{mg}$ of acetylsalicylic acid. Streptokinase was given in coronary care unit under strict observation and monitoring during hospital stay. Patients with ST elevation myocardial infarction were observed for evidence of both in hospital morbidity and mortality.

\begin{tabular}{|c|c|c|c|}
\hline \multicolumn{2}{|r|}{ Variables } & Mean \pm SD & Range \\
\hline \multirow{2}{*}{\multicolumn{2}{|c|}{ Age (years) }} & $56.3 \pm 9.3$ & $34.0-80.0$ \\
\hline & & $\mathrm{N}$ & $\%$ \\
\hline \multirow[t]{2}{*}{ Sex } & Male & 84 & 70.0 \\
\hline & Female & 36 & 30.0 \\
\hline \multicolumn{2}{|r|}{ Smoking } & 67 & 55.8 \\
\hline \multicolumn{2}{|r|}{ HTN } & 69 & 57.5 \\
\hline \multicolumn{2}{|r|}{$\mathrm{DM}$} & 64 & 53.3 \\
\hline \multicolumn{2}{|r|}{ Dyslipidemia } & 18 & 15.0 \\
\hline \multicolumn{2}{|r|}{ Family history for IHD } & 13 & 10.8 \\
\hline \multirow{2}{*}{\multicolumn{2}{|c|}{ Previous PCI }} & 7 & 5.8 \\
\hline & Previous MI & 30 & 25.0 \\
\hline
\end{tabular}

Table 2:-Baseline characteristics of the study group

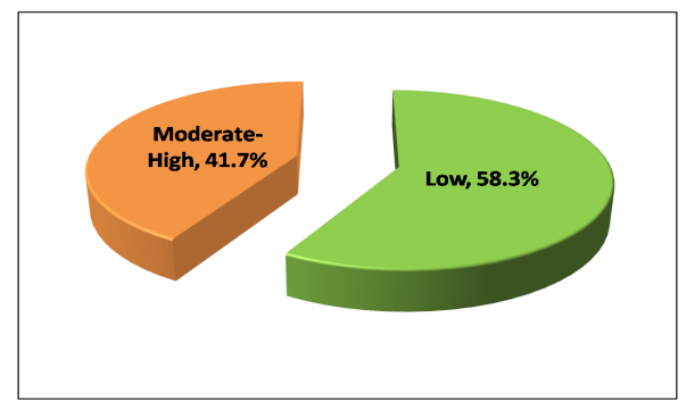

Figure 1:-GRACE score among the studied cases

Data were analyzed using Statistical program for social science (SPSS) version 20.0. Quantitative data were expressed as mean \pm standard deviation (SD). Qualitative data were expressed as frequency and percentage. Independent samples t-test of significance was used when comparing between two means. Chi-square (X2) test of significance was used in order to compare proportions between two qualitative parameters.

\section{Results:-}

This was a prospective cross sectional observational study that involved 120 patients who presented to the emergency department of AL-Azhar University Hospital and Al Matareya Teaching Hospital (MTH) with acute STEMI and treated with thrombolytics, within the period between March 2017 to February 2018.

The Mean age was 56.3 \pm 9.3 years (ranged from 34-80 years). Males represented $70 \%$ ( 84 patients) of the study population while females represented $30 \%$ (36 patients). Fifty seven percent (69 patients) were hypertensive while fifty three percent (64 patients) were diabetic and fifty five percent (67 patients) were smokers. Fifteen percent of study group (18 patients) had history of dyslipidemia. Ten percent (13 patients) have positive family history of ischemic heart disease. Twenty five percent of the study group (30 patients) gave us a history of old myocardial infarction and five percent (7 patients) had previous PCI.

As regard clinical examination, the mean onset of chest pain was 5.1 \pm 2.1 . The mean heart rate (HR) was $97.9 \pm 21.7$ Bpm, the mean of systolic blood pressure (SBP) was $126.6 \pm 28.5 \mathrm{mmHg}$, the mean of diastolic blood pressure (DBP) was $77.2 \pm 17.7 \mathrm{mmHg}$. The mean serum creatnine was $1.23 \pm 0.51 \mathrm{mg} / \mathrm{dl}$, the mean serum urea was $38.0 \pm 11.9 \mathrm{mg} / \mathrm{dl}$, the mean haemoglobin during hospital stay was $13.6 \pm 1.4 \mathrm{gm} / \mathrm{dl}$, the mean random blood sugar on admission was $284.7 \pm 97.6 \mathrm{gm} / \mathrm{dl}$ and the mean ejection fraction during hospital stay was $51.7 \pm 8.1 \%$ ranged from $30.0-68.0 \%$.

\begin{tabular}{|c|c|c|}
\hline Variables & Mean \pm SD & Range \\
\hline Total score & $113.1 \pm 26.0$ & $56.0-165.0$ \\
\hline
\end{tabular}




\begin{tabular}{|c|c|c|c|}
\hline \multicolumn{2}{|c|}{} & $\mathrm{N}$ & $\%$ \\
\hline \multirow{2}{*}{ Risk } & Low & 70 & 58.3 \\
\cline { 2 - 4 } & Moderate-High & 50 & 41.7 \\
\hline
\end{tabular}

Table 3:-GRACE score among the studied cases.

In our study group, the mean GRACE score was $113.1 \pm 26$ ranged from 56.0-165.0. The percentage of the patients with low GRACE score was 58.3\% ( 70 patients ) while the percentage of the patients with moderate to high GRACE score was $41.7 \%$ ( 50 patients ).

Figure 2:-Follow up complications among the studied cases.

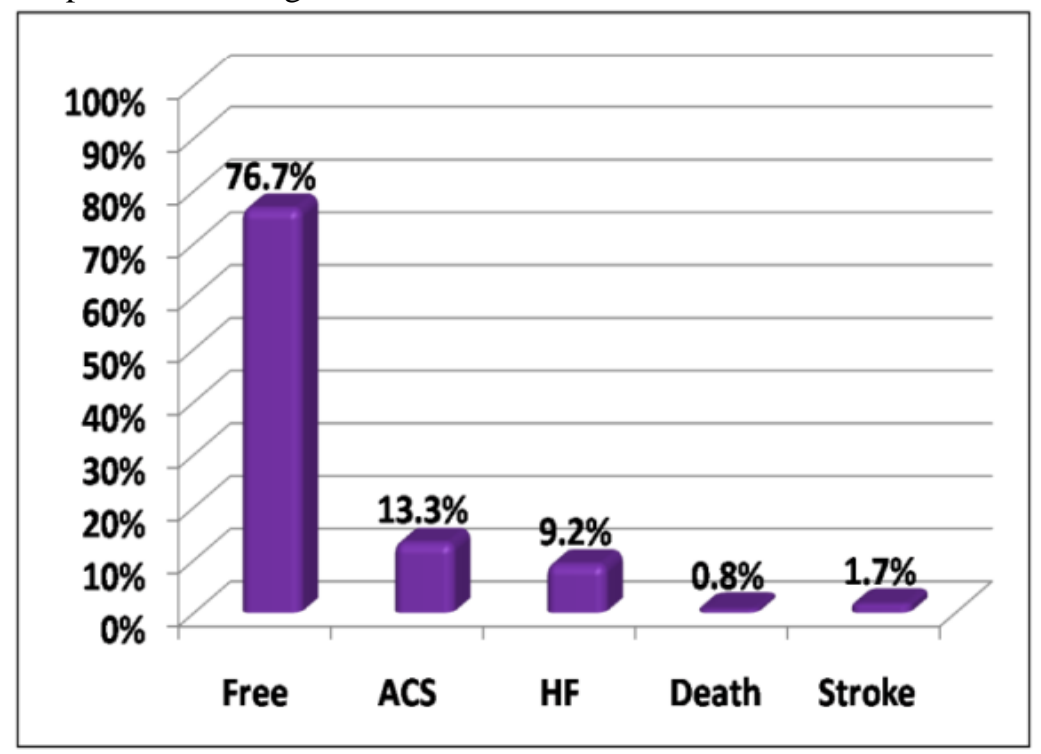

Among the study group, the mean time from fibrinolysis to PCI is $7.8 \pm 3.5$ with 94 patients had culprit PCI and 26 patients had multivessel PCI. Among those patients, 86 patients had one stent and 29 patients had two stents and 2 patients had more than two stents while 3 patients had only PTCA. Also, 65 patients had single vessel disease, 44 patients had two vessel disease and 11 patients had more than two vessel disease.

\begin{tabular}{|c|c|c|c|}
\hline & & Mean \pm SD & Range \\
\hline \multicolumn{2}{|c|}{ Time from fibrinolysis to PCI (days) } & $7.8 \pm 3.5$ & $2.0-14.0$ \\
\hline & & $\mathrm{N}$ & $\%$ \\
\hline \multirow[t]{2}{*}{ PCI } & Culprit & 94 & 78.3 \\
\hline & Multivessel & 26 & 21.7 \\
\hline \multirow[t]{3}{*}{ Number } & Single & 65 & 54.2 \\
\hline & Two & 44 & 36.7 \\
\hline & Multiple & 11 & 9.2 \\
\hline \multirow[t]{4}{*}{ Stent } & None & 3 & 2.5 \\
\hline & One & 86 & 71.7 \\
\hline & Two & 29 & 24.2 \\
\hline & Multiple & 2 & 1.7 \\
\hline \multirow[t]{4}{*}{ Complications during PCI } & None & 114 & 95.0 \\
\hline & Thrombus & 4 & 3.3 \\
\hline & Slow flow & 1 & 0.8 \\
\hline & Dissection & 1 & 0.8 \\
\hline
\end{tabular}

Table 3:-Procedural data among the studied cases.

This study showed that more than three quarters of the studied cases had no follow up complications and the most frequent complication was ACS. The percentage of cases which had ACS was 13.3\% (number of patients 16), the 
percentage of cases with HF was 9.2\% (number of patients 11), the percentage of cases with stroke was $1.7 \%$ (2 patients) and only one case died

There was no statistically significant difference between the two groups regarding demographic characteristics and comorbidities.

Cases with complication had statistically significant higher HR ( $\mathrm{p}$ value $=0.027$ ), killip classification ( $\mathrm{p}$ value $=0.004)$, history of cardiac arrest $(\mathrm{p}$ value $=0.012$ ) and total GRACE score ( $\mathrm{p}$ value $=0.001$ ) and statistically significant lower ejection fraction ( $\mathrm{p}$ value $=0.016$ ).

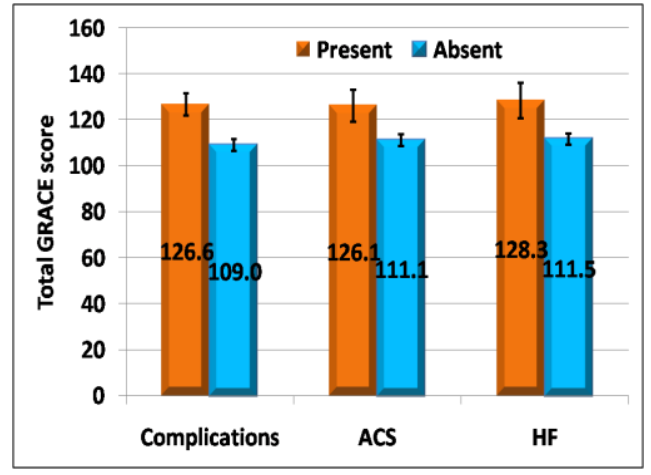

Figure 3:-GRACE score among different complications

Cases with cardiovascular complications had significantly higher time from successful fibrinolysis to PCI ( $\mathrm{p}$ value $<0.001)$.

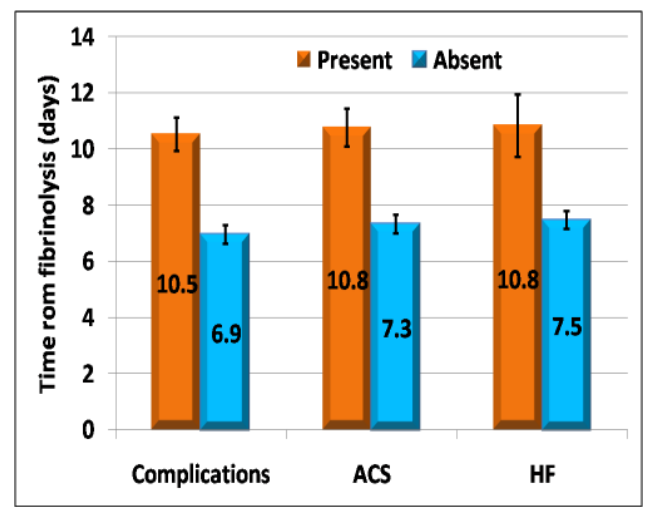

Figure 4:-Time from fibrinolysis to PCI among different complications.

There was statistically significant positive correlation between rate of complication and HR ( $p$ value $=0.027$ ), Killip classification ( $p$ value $=0.004)$, cardiac arrest on hospital admission $(p$ value $=0.001)$ and total GRACE score $(p$ value $<0.001$ ) and negative correlations with ejection fraction ( $\mathrm{p}$ value $=0.016$ ). Cases with cardiovascular complications had significantly higher time from successful fibrinolysis to PCI( $\mathrm{p}$ value $<0.001$ ). Cases with ACS had significantly higher total GARACE Score $(\mathrm{p}$ value $=0.031$ ) and lower hemoglobin level $(\mathrm{p}$ value $=0.013)$. Also, cases with ACS had significantly higher time from fibrinolysis and more frequent procedural complications ( $\mathrm{p}$ value $<0.011$ ). There was statistically significant positive correlation between rate of HF and Killip classification ( $\mathrm{p}$ value $=0.011)$, cardiac arrest on hospital admission $(\mathrm{p}$ value $=0.018)$ and total GRACE score $(\mathrm{p}$ value $=0.041)$ and negative correlations with ejection fraction ( $\mathrm{p}$ value $=0.006$ ). Cases with $\mathrm{HF}$ had significantly higher time from fibrinolysis to revascularization ( $\mathrm{p}$ value $=0.002$ ).

GRACE and time from fibrinolysis to PCI were significant factors that affect complications, ACS and HF, while EF was a significant factor that affects complications and HF. 
Figure 5:-ROC curve for GRACE, time from fibrinolysis, EF and regression probability in prediction of complications

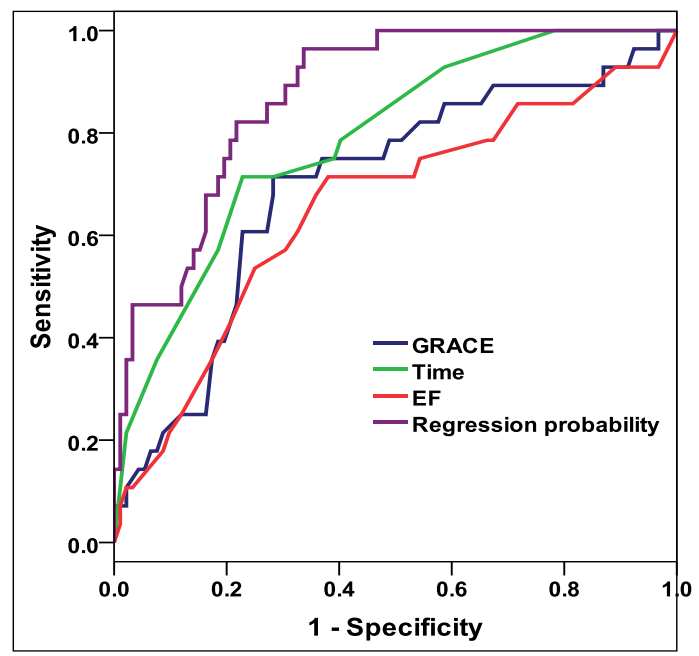

Figure 6:-ROC curve for GRACE, time from fibrinolysis, EF and regression probability in prediction of ACS.

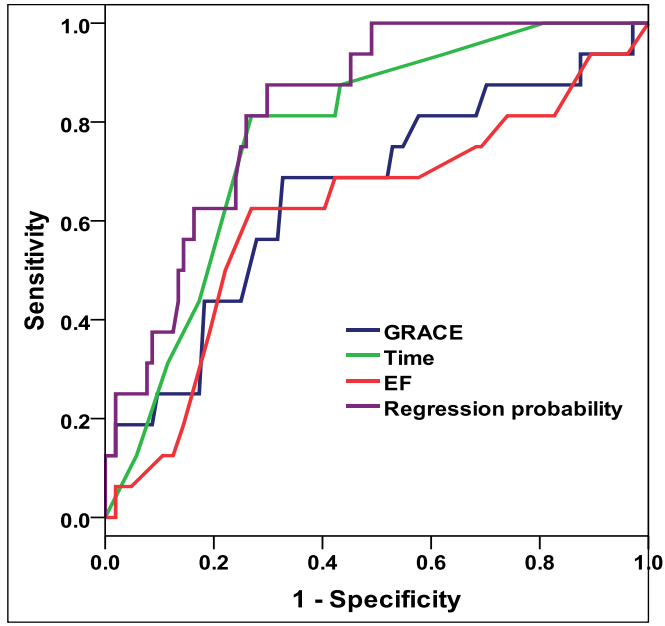

Figure 7:-ROC curve for GRACE, time from fibrinolysis to PCI, EF and regression probability in prediction of HF

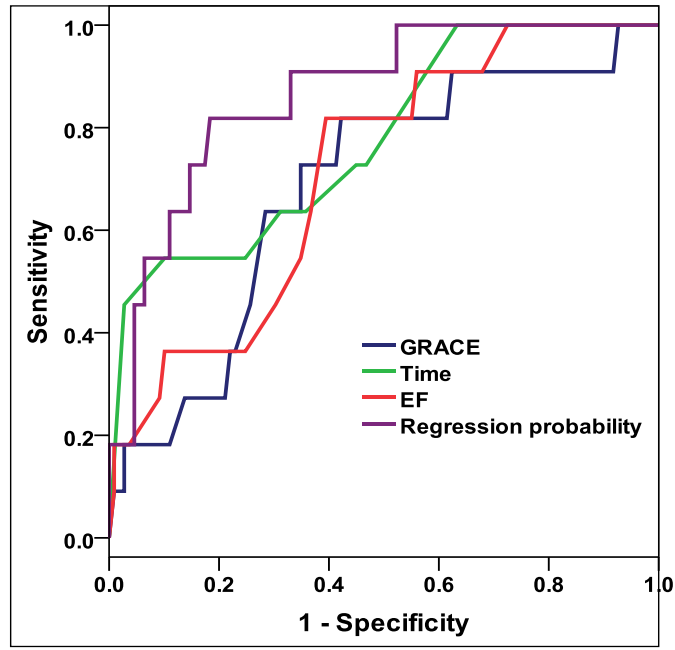




\title{
Predicting probability for any complication:- \\ $\operatorname{Exp}(-6.933+(0.047 *$ GRACE $)+(0.419 *$ Time $)+(-0.070 * \mathrm{EF})) /(1+(\operatorname{Exp}(-6.933+(0.047 * \mathrm{GRACE})+(0.419 * \mathrm{Time})))$
}

\author{
Predicting probability for any ACS:- \\ $\operatorname{Exp}(-9.140+(0.033 *$ GRACE $)+(0.360+$ Time $)) /(1+(\operatorname{Exp}(-9.140+(0.033 *$ GRACE $)+(0.360+$ Time $)))$ \\ Predicting probability for any HF:- \\ $\operatorname{Exp}((0.019 * \mathrm{GRACE})+(0.242 * \mathrm{Time})+(-0.137 * \mathrm{EF})) /(1+(\operatorname{Exp}((0.019 * \mathrm{GRACE})+(0.242 * \mathrm{Time})+(-0.137 * \mathrm{EF})))$
}

\section{Discussion:-}

Although early pharmacoinvasive strategy (within 2-24 h) after successful reperfusion is recommended by several guidelines [10], timely fashion coronary intervention is not widely available in countries with limited PCI capable hospitals including Egypt. Several randomized trials and meta-analysis have shown that early routine post thrombolysis angiography with subsequent PCI reduced the rates of re-infarction and recurrent ischemia compared with a watchful waiting strategy, in which angiography and revascularization were indicated only in the patients with spontaneous or induced severe ischemia or left ventricular (LV) dysfunction. The benefits of early routine PCI after thrombolysis were seen in the absence of increased risk of adverse events in many studies [11].

Many studies and meta-analysis demonstrated the accuracy and the usefulness of the GRACE score on the mortality of ACS patients in hospital and follow-up after hospital discharged [12].

Because of geographic and long distance of transfer and few of number of interventional cardiologists, primary PCI and routine PCI after successful fibrinolysis were very difficult for this situation. Several studies demonstrated the worst cardiovascular outcomes in patients who received delay coronary intervention after thrombolysis [13].

Risk stratification of the STEMI patients was very important for the clinicians in non-PCI capable hospital to use to guide selection of the STEMI patients for early invasive strategy. GRACE risk score, one of clinical risk scores, has been shown to be a good risk stratification score in population with STEMI and NSTE-ACS.

The current study aimed to evaluate the prognostic utility of the GRACE score among an Egyptian cohort in a prospective cross sectional observational study conducted at Al-Azhar University Hospital and EL-Matarya Teaching Hospital (MTH) and involved 120 patients who presented with (STEMI) and received successful fibrinolysis, from March 2017 to February 2018.

This study showed that more than three quarters of the studied cases had no follow up complications and the most frequent complication was ACS. The percentage of cases which had ACS was 13.3\% (number of patients 16), the percentage of cases with $\mathrm{HF}$ was $9.2 \%$ (number of patients 11)

Our study demonstrated that the long delay in intermediate to high GRACE score patients after successful fibrinolysis in non PCI-capable facilities was associated with worse cardiovascular outcomes (death, re-hospitalized with ACS, re-hospitalized with HF and stroke) than the patients with low GRACE score (P value <0.001) and this was concordant with the Southwest German Interventional Study in Acute Myocardial infarction (SIAM III) which evaluated the effects of transfer early PCI (within 6h after fibrinolysis) compared with delay PCI strategy (elective PCI 2 weeks after fibrinolysis). Early PCI showed significant reduction of primary end point (death, re-infarction, target lesion revascularization (TLR) and ischemic events) $(\mathrm{p}=0.008)$ and higher long term survival than delayed PCI $(\mathrm{p}=0.057)[14]$.

Similarly, The Trial of Routine Angioplasty and Stenting after Fibrinolysis to Enhance Reperfusion in Acute Myocardial Infarction (TRANSFER-AMI) trial showed that the patients who transfer from non-PCI center within 6 $\mathrm{h}$ after thrombolysis had fewer ischemic complications than standard treatment (delayed PCI) without increasing of major bleeding [15].

Also, The NORwegian study onDistrict treatment of ST-Elevation Myocardial infarction (NORDISTEMI) study also demonstrated a significant reduction in the composite cardiovascular outcome (death, re-infarction, stroke, or recurrent ischemia) at 1 year in the patients with immediate transferred to PCI following with thrombolysis as compared with the patients in conservative arm treatment ( $6 \%$ vs $16 \%, p=0.01)$ [7]. 
The Combined Abciximab RE-teplase Stent Study in Acute Myocardial Infarction (CARESS- AMI) study, a more conservative strategy (i.e. angiogram only in cases of failed thrombolysis) was associated with a worse clinical outcome than the strategy of angiogram and intervention (if indicated) in all cases following thrombolysis (composite of death, re-infarction and refractory ischemia at 30-day, $11 \%$ vs $4 \%, \mathrm{p}=0.004$ ) [16].

On the data from CARESS-AMI [16] and TRANSFER-AMI [15], The American College of Cardiology (ACC) and the American heart association (AHA) a class IIa recommendations were given for high risk features (such as Kilip class $>2$, extensive ST-elevation, left ventricular ejection fraction (LVEF) $<35 \%$, or hypotension) and should be immediatly transferred to PCI-capable facilities [17]. The transfer of low and moderate risk STEMI patients to PCIcapable center received a class IIb recommendation.

\begin{tabular}{|c|c|c|c|c|}
\hline & & $\begin{array}{c}\text { Complication } \\
(\mathrm{N}=28)\end{array}$ & $\begin{array}{c}\text { No } \\
(\mathrm{N}=92)\end{array}$ & $\mathrm{P}$ \\
\hline \multicolumn{2}{|c|}{ Onset (hours) } & $5.1 \pm 1.9$ & $5.1 \pm 2.2$ & $\wedge^{\wedge} 0.984$ \\
\hline \multicolumn{2}{|c|}{ HR (Beat/minute) } & $105.8 \pm 18.5$ & $95.5 \pm 22.1$ & $\wedge 0.027 *$ \\
\hline \multicolumn{2}{|c|}{ SBP $(\mathrm{mmHg})$} & $126.3 \pm 30.3$ & $126.7 \pm 28.1$ & $\wedge^{\wedge} 0.944$ \\
\hline \multicolumn{2}{|c|}{ DBP $(\mathrm{mmHg})$} & $74.8 \pm 20.7$ & $77.9 \pm 16.7$ & ${ }^{\wedge} 0.424$ \\
\hline \multicolumn{2}{|c|}{ Serum creatinine $(\mathrm{mg} / \mathrm{dL})$} & $1.36 \pm 0.51$ & $1.20 \pm 0.51$ & ${ }^{\wedge} 0.146$ \\
\hline \multicolumn{2}{|c|}{ Serum urea $(\mathrm{mg} / \mathrm{dL})$} & $40.2 \pm 13.0$ & $37.3 \pm 11.5$ & ${ }^{\wedge} 0.261$ \\
\hline \multirow{2}{*}{\multicolumn{2}{|c|}{$\begin{array}{c}\mathrm{Hb}(\mathrm{gm} / \mathrm{dL}) \\
\mathrm{FBG}(\mathrm{gm} / \mathrm{dL})\end{array}$}} & $13.2 \pm 1.3$ & $13.7 \pm 1.5$ & ${ }^{\wedge} 0.107$ \\
\hline & & $278.2 \pm 108.9$ & $286.7 \pm 94.5$ & $\wedge 0.689$ \\
\hline \multicolumn{2}{|c|}{$\mathrm{EF} \%$} & $48.5 \pm 9.3$ & $52.6 \pm 7.5$ & $\wedge^{\wedge} 0.016^{*}$ \\
\hline \multirow[t]{3}{*}{ Killip Class } & $\mathrm{I}$ & $14(50.0 \%)$ & $73(79.3 \%)$ & \multirow[t]{3}{*}{$20.004^{*}$} \\
\hline & II & $13(46.4 \%)$ & $15(16.3 \%)$ & \\
\hline & III & $1(3.6 \%)$ & $4(4.3 \%)$ & \\
\hline \multicolumn{2}{|c|}{ DKA } & $3(10.7 \%)$ & $6(6.5 \%)$ & $\not 0.434$ \\
\hline \multicolumn{2}{|c|}{ Crepitation } & $19(67.9 \%)$ & $48(52.2 \%)$ & \#0.143 \\
\hline \multicolumn{2}{|c|}{ Tachyarythmia } & $7(25.0 \%)$ & $14(15.2 \%)$ & $\not 0.260$ \\
\hline \multicolumn{2}{|c|}{ Bradyarrythmia } & $1(3.6 \%)$ & $9(9.8 \%)$ & $\not 0.450$ \\
\hline \multicolumn{2}{|c|}{ Cardiac arrest } & $7(25.0 \%)$ & $4(4.3 \%)$ & $20.012 *$ \\
\hline \multirow[t]{3}{*}{ Site (ECG) } & Anterior & $18(64.3 \%)$ & $51(55.4 \%)$ & \multirow[t]{3}{*}{$\mathrm{x} 0.290$} \\
\hline & Inferior & $8(28.6 \%)$ & $38(41.3 \%)$ & \\
\hline & Both & $2(7.1 \%)$ & $3(3.3 \%)$ & \\
\hline \multicolumn{2}{|c|}{ Total grace score } & $126.6 \pm 25.2$ & $109.0 \pm 24.9$ & $\wedge^{\wedge} 0.001 *$ \\
\hline \multirow[t]{2}{*}{ Risk } & Low & $8(28.6 \%)$ & $62(67.4 \%)$ & \multirow[t]{2}{*}{$<0.001 *$} \\
\hline & Moderate-High & $20(71.4 \%)$ & $30(32.6 \%)$ & \\
\hline
\end{tabular}

Table 4:-Comparison between cases with and without complications regarding clinical condition and laboratory findings at presentation

\begin{tabular}{|c|c|c|c|c|}
\hline & & $\begin{array}{c}\text { Complication } \\
(\mathrm{N}=28)\end{array}$ & $\begin{array}{c}\mathrm{N} \\
(\mathrm{N}=92)\end{array}$ & $\mathrm{P}$ value \\
\hline \multicolumn{2}{|c|}{ Time from fibrinolysis (days) } & $10.5 \pm 3.1$ & $6.9 \pm 3.2$ & $\wedge<0.001 *$ \\
\hline \multirow[t]{2}{*}{ PCI } & Culprit & $22(78.6 \%)$ & $72(78.3 \%)$ & \multirow[t]{2}{*}{$\# 1.000$} \\
\hline & Multivessel & $6(21.4 \%)$ & $20(21.7 \%)$ & \\
\hline \multirow[t]{3}{*}{ Affection } & Single & $12(42.9 \%)$ & $53(57.6 \%)$ & \multirow[t]{3}{*}{$\# 0.247$} \\
\hline & Two & $14(50.0 \%)$ & $30(32.6 \%)$ & \\
\hline & Multiple & $2(7.1 \%)$ & $9(9.8 \%)$ & \\
\hline \multirow[t]{4}{*}{ Stent } & None & $0(0.0 \%)$ & $3(3.3 \%)$ & \multirow[t]{4}{*}{20.365} \\
\hline & One & $18(64.3 \%)$ & $68(73.9 \%)$ & \\
\hline & Two & $9(32.1 \%)$ & $20(21.7 \%)$ & \\
\hline & Multiple & $1(3.6 \%)$ & $1(1.1 \%)$ & \\
\hline \multicolumn{2}{|c|}{ Complications } & $3(10.7 \%)$ & $3(3.3 \%)$ & 90.139 \\
\hline
\end{tabular}

Table 5:-Comparison between cases with and without complications regarding procedural data 


\begin{tabular}{|c|c|c|c|c|}
\hline \multicolumn{2}{|c|}{ variables } & $\begin{array}{c}\text { ACS } \\
(\mathrm{N}=16)\end{array}$ & $\begin{array}{c}\text { No } \\
(\mathrm{N}=104)\end{array}$ & $\mathrm{P}$ \\
\hline \multicolumn{2}{|c|}{ Onset (hours) } & $5.7 \pm 1.5$ & $5.0 \pm 2.2$ & ${ }^{\wedge} 0.128$ \\
\hline \multicolumn{2}{|c|}{ HR (Beat/minute) } & $101.6 \pm 21.2$ & $97.4 \pm 21.8$ & $\wedge^{\wedge} 0.466$ \\
\hline \multicolumn{2}{|c|}{$\mathrm{SBP}(\mathrm{mmHg})$} & $135.6 \pm 33.7$ & $125.2 \pm 27.5$ & $\wedge^{\wedge} 0.174$ \\
\hline \multicolumn{2}{|c|}{$\mathrm{DBP}(\mathrm{mmHg})$} & $79.1 \pm 23.1$ & $76.9 \pm 16.8$ & $\wedge 0.720$ \\
\hline \multicolumn{2}{|c|}{ Serum creatinine $(\mathrm{mg} / \mathrm{dL})$} & $1.40 \pm 0.55$ & $1.21 \pm 0.51$ & $\wedge 0.165$ \\
\hline \multicolumn{2}{|c|}{ Serum urea $(\mathrm{mg} / \mathrm{dL})$} & $43.0 \pm 13.4$ & $37.2 \pm 11.5$ & $\wedge 0.068$ \\
\hline \multicolumn{2}{|c|}{$\mathrm{Hb}(\mathrm{gm} / \mathrm{dL})$} & $12.9 \pm 1.0$ & $13.7 \pm 1.5$ & ${ }^{\wedge} 0.013^{*}$ \\
\hline \multicolumn{2}{|c|}{ FBG (mgm/dL) } & $276.6 \pm 95.8$ & $286.0 \pm 98.3$ & ${ }^{\wedge} 0.721$ \\
\hline \multicolumn{2}{|c|}{$\mathrm{EF} \%$} & $49.2 \pm 8.9$ & $52.0 \pm 7.9$ & ${ }^{\wedge} 0.189$ \\
\hline \multirow[t]{3}{*}{ KillipClas } & I & $10(62.5 \%)$ & $77(74.0 \%)$ & \multirow[t]{3}{*}{$a 0.435$} \\
\hline & II & $5(31.3 \%)$ & $23(22.1 \%)$ & \\
\hline & III & $1(6.3 \%)$ & $4(3.8 \%)$ & \\
\hline \multicolumn{2}{|c|}{ DKA } & $0(0.0 \%)$ & $9(8.7 \%)$ & $a 0.606$ \\
\hline \multicolumn{2}{|c|}{ Basal Crepitaion } & $10(62.5 \%)$ & $57(54.8 \%)$ & $\# 0.564$ \\
\hline \multicolumn{2}{|c|}{ Tachyarythmia } & $4(25.0 \%)$ & $17(16.3 \%)$ & $\not 0.478$ \\
\hline \multicolumn{2}{|c|}{ Bradyarrythmia } & $1(6.3 \%)$ & $9(8.7 \%)$ & $\$ 1.000$ \\
\hline \multicolumn{2}{|c|}{ Cardiac Arrest } & $3(18.8 \%)$ & $10(9.6 \%)$ & 0.379 \\
\hline \multirow[t]{3}{*}{ Site (ECG) } & Anterior & $10(62.5 \%)$ & $59(56.7 \%)$ & \multirow[t]{3}{*}{$a 0.634$} \\
\hline & Inferior & $5(31.3 \%)$ & $41(39.4 \%)$ & \\
\hline & Both & $1(6.3 \%)$ & $4(3.8 \%)$ & \\
\hline \multicolumn{2}{|c|}{ Total grace score } & $126.1 \pm 28.0$ & $111.1 \pm 25.2$ & ${ }^{\wedge} 0.031^{*}$ \\
\hline \multirow[t]{2}{*}{ Risk } & Low & $5(31.3 \%)$ & $65(62.5 \%)$ & \multirow[t]{2}{*}{$\# 0.018^{*}$} \\
\hline & Moderate-High & $11(68.8 \%)$ & $39(37.5 \%)$ & \\
\hline
\end{tabular}

Table 5:-Comparison between cases with and without ACS regarding clinical condition and laboratory findings at presentation

\begin{tabular}{|c|c|c|c|c|}
\hline & & $\begin{array}{c}\text { ACS } \\
(\mathrm{N}=16)\end{array}$ & $\begin{array}{c}\text { No } \\
(\mathrm{N}=104)\end{array}$ & $\mathrm{P}$ \\
\hline \multicolumn{2}{|c|}{ Time from fibrinolysis (days) } & $10.8 \pm 2.7$ & $7.3 \pm 3.4$ & $\wedge<0.001^{*}$ \\
\hline \multirow[t]{2}{*}{ PCI } & Culprit & $13(81.3 \%)$ & $81(77.9 \%)$ & \multirow[t]{2}{*}{$\not 1.000$} \\
\hline & Multivessel & $3(18.8 \%)$ & $23(22.1 \%)$ & \\
\hline \multirow[t]{3}{*}{ Affection } & Single & $8(50.0 \%)$ & $57(54.8 \%)$ & \multirow[t]{3}{*}{$\# 0.226$} \\
\hline & Two & $8(50.0 \%)$ & $36(34.6 \%)$ & \\
\hline & Multi & $0(0.0 \%)$ & $11(10.6 \%)$ & \\
\hline \multirow[t]{4}{*}{ Stent } & None & $3(2.9 \%)$ & $0(0.0 \%)$ & \multirow[t]{4}{*}{$a 0.571$} \\
\hline & One & $76(73.1 \%)$ & $10(62.5 \%)$ & \\
\hline & Two & $23(22.1 \%)$ & $6(37.5 \%)$ & \\
\hline & Multiple & $2(1.9 \%)$ & $0(0.0 \%)$ & \\
\hline \multicolumn{2}{|c|}{ Complications } & $3(18.8 \%)$ & $3(2.9 \%)$ & a0.031* \\
\hline
\end{tabular}

Table 6:-Comparison between cases with and without ACS regarding procedural data

\begin{tabular}{|c|c|c|c|}
\hline & HF $(\mathrm{N}=11)$ & No $(\mathrm{N}=109)$ & $\mathrm{P}$ \\
\hline Onset (hours) & $4.7 \pm 2.0$ & $5.1 \pm 2.1$ & ${ }^{\wedge} 0.543$ \\
\hline HR (Beat/minute) & $108.4 \pm 15.6$ & $96.9 \pm 22.0$ & ${ }^{\wedge} 0.094$ \\
\hline SBP (mmHg) & $121.4 \pm 29.7$ & $127.1 \pm 28.4$ & ${ }^{\wedge} 0.526$ \\
\hline DBP (mmHg) & $74.5 \pm 23.0$ & $77.4 \pm 17.1$ & ${ }^{\wedge} 0.607$ \\
\hline Serum creatinine (mg/dL) & $1.35 \pm 0.46$ & $1.22 \pm 0.52$ & ${ }^{\wedge} 0.450$ \\
\hline Serum urea (mg/dL) & $36.5 \pm 12.5$ & $38.1 \pm 11.8$ & ${ }^{\wedge} 0.659$ \\
\hline Hb (gm/dL) & $13.2 \pm 1.3$ & $13.6 \pm 1.5$ & ${ }^{\wedge} 0.316$ \\
\hline FBG (gm/dL) & $286.7 \pm 135.1$ & $284.5 \pm 93.9$ & ${ }^{\wedge} 0.943$ \\
\hline EF\% & $45.4 \pm 8.5$ & $52.3 \pm 7.8$ & ${ }^{\wedge} 0.006^{*}$ \\
\hline Kilib Class I & $4(36.4 \%)$ & $83(76.1 \%)$ & $\mathrm{q}^{*} 0.011^{*}$ \\
\hline
\end{tabular}




\begin{tabular}{|c|c|c|c|c|}
\hline & II & $7(63.6 \%)$ & $21(19.3 \%)$ & \\
\hline & III & $0(0.0 \%)$ & $5(4.6 \%)$ & \\
\hline \multicolumn{2}{|c|}{ DKA } & $2(18.2 \%)$ & $7(6.4 \%)$ & a0.193 \\
\hline \multicolumn{2}{|c|}{ Crepitaion } & $8(72.7 \%)$ & $59(54.1 \%)$ & $a 0.343$ \\
\hline \multicolumn{2}{|c|}{ Tachyarythmia } & $3(27.3 \%)$ & $18(16.5 \%)$ & $\mathrm{a} 0.405$ \\
\hline \multicolumn{2}{|c|}{ Bradyarrythmia } & $0(0.0 \%)$ & $10(9.2 \%)$ & a0.596 \\
\hline \multicolumn{2}{|c|}{ Cardiac arrest } & $4(36.4 \%)$ & $9(8.3 \%)$ & $\not 0.018 *$ \\
\hline \multirow[t]{3}{*}{ Site (ECG) } & Anterior & $9(81.8 \%)$ & $60(55.0 \%)$ & \multirow[t]{3}{*}{$\not a 0.286$} \\
\hline & Inferior & $2(18.2 \%)$ & $44(40.4 \%)$ & \\
\hline & Both & $0(0.0 \%)$ & $5(4.6 \%)$ & \\
\hline \multicolumn{2}{|c|}{ Total grace score } & $128.3 \pm 25.1$ & $111.5 \pm 25.7$ & $\wedge 0.041 *$ \\
\hline \multirow[t]{2}{*}{ Risk } & Low & $3(27.3 \%)$ & $67(61.5 \%)$ & \multirow{2}{*}{$\begin{array}{c}\not a \\
0.049 *\end{array}$} \\
\hline & Moderate-High & $8(72.7 \%)$ & $42(38.5 \%)$ & \\
\hline
\end{tabular}

Table 7:-Comparison between cases with and without HF regarding clinical condition and laboratory findings at presentation.

\begin{tabular}{|c|c|c|c|c|}
\hline & & $\mathrm{HF}(\mathrm{N}=11)$ & No $(N=109)$ & $\mathrm{P}$ \\
\hline \multicolumn{2}{|c|}{ Time from fibrinolysis (days) } & $10.8 \pm 3.7$ & $7.5 \pm 3.4$ & $\wedge 0.002 *$ \\
\hline \multirow[t]{2}{*}{ PCI } & Culprit & $9(81.8 \%)$ & $85(78.0 \%)$ & \multirow[t]{2}{*}{$\not 1.000$} \\
\hline & Multivessel & $2(18.2 \%)$ & $24(22.0 \%)$ & \\
\hline \multirow[t]{3}{*}{ Affection } & Single & $5(45.5 \%)$ & $60(55.0 \%)$ & \multirow[t]{3}{*}{$a 0.505$} \\
\hline & Two & $4(36.4 \%)$ & $40(36.7 \%)$ & \\
\hline & Multi & $2(18.2 \%)$ & $9(8.3 \%)$ & \\
\hline \multirow[t]{4}{*}{ Stent } & None & $0(0.0 \%)$ & $3(2.8 \%)$ & \multirow[t]{4}{*}{$a 0.319$} \\
\hline & One & $8(72.7 \%)$ & $78(71.6 \%)$ & \\
\hline & Two & $2(18.2 \%)$ & $27(24.8 \%)$ & \\
\hline & Multiple & $1(9.1 \%)$ & $1(0.9 \%)$ & \\
\hline \multicolumn{2}{|c|}{ Complications } & $0(0.0 \%)$ & $6(5.5 \%)$ & $\not 1.000$ \\
\hline
\end{tabular}

Table 8:-Comparison between cases with and without HF regarding procedural data

\begin{tabular}{|c|c|c|c|c|c|}
\hline Factors & $\mathbf{A U C}$ & SE & $\mathbf{P}$ & $95 \% \mathrm{CI}$ & Cut off \\
\hline \multicolumn{6}{|c|}{ Complications } \\
\hline GRACE & 0.696 & 0.058 & $0.002 *$ & $0.582-0.810$ & $\geq 127.0$ \\
\hline Time & 0.787 & 0.047 & $<0.001 *$ & $0.696-0.879$ & $\geq 9.0$ \\
\hline $\mathbf{E F}$ & 0.653 & 0.063 & $0.014 *$ & $0.530-0.776$ & $\leq 51.0$ \\
\hline Regression probability & 0.872 & 0.032 & $<0.001^{*}$ & $0.809-0.936$ & $\geq 0.135$ \\
\hline \multicolumn{6}{|c|}{$\mathbf{A C S}$} \\
\hline GRACE & 0.660 & 0.078 & $0.040 *$ & $0.508-0.812$ & $\geq 127.0$ \\
\hline Time & 0.775 & 0.054 & $<0.001^{*}$ & $0.669-0.880$ & $\geq 9.0$ \\
\hline EF & 0.619 & 0.081 & 0.127 & $0.459-0.778$ & -- \\
\hline Regression probability & 0.844 & 0.038 & $<0.001^{*}$ & $0.769-0.919$ & $\geq 0.135$ \\
\hline \multicolumn{6}{|c|}{ HF } \\
\hline GRACE & 0.685 & 0.082 & $0.043 *$ & $0.525-0.845$ & $\geq 116.0$ \\
\hline Time & 0.776 & 0.074 & $0.003 *$ & $0.630-0.921$ & $\geq 13.0$ \\
\hline EF & 0.714 & 0.071 & $0.020 *$ & $0.574-0.853$ & $\leq 51.0$ \\
\hline Regression probability & 0.844 & 0.054 & $<0.001^{*}$ & $0.739-0.950$ & $\geq 0.109$ \\
\hline
\end{tabular}

Table 9:-Diagnostic performance of GRACE, time from fibrinolysis, EF and regression probability in prediction of complications 


\begin{tabular}{|c|c|c|c|c|}
\hline Characters & Value & \multicolumn{1}{|c|}{$\mathbf{9 5 \%}$ CI } & \multicolumn{1}{c|}{ Value } & \multicolumn{2}{c|}{ 95\% CI } \\
\hline & \multicolumn{2}{|c|}{ GRACE $\geq \mathbf{1 2 7 . 0}$} & \multicolumn{2}{c|}{ Time } \\
\hline Sensitivity & $71.4 \%$ & $51.3 \%-86.8 \%$ & $71.4 \%$ & $51.3 \%-86.8 \%$ \\
\hline Specificity & $68.5 \%$ & $58.0 \%-77.8 \%$ & $72.8 \%$ & $62.6 \%-81.6 \%$ \\
\hline DA & $69.2 \%$ & $60.1 \%-77.3 \%$ & $72.5 \%$ & $63.6 \%-80.3 \%$ \\
\hline Youden's index & $39.9 \%$ & $20.7 \%-59.1 \%$ & $44.3 \%$ & $25.2 \%-63.3 \%$ \\
\hline PPV & $40.8 \%$ & $27.0 \%-55.8 \%$ & $44.4 \%$ & $29.6 \%-60.0 \%$ \\
\hline NPV & $88.7 \%$ & $79.0 \%-95.0 \%$ & $89.3 \%$ & $80.1 \%-95.3 \%$ \\
\hline LR+ & 2.27 & $1.55-3.32$ & 2.63 & $1.75-3.95$ \\
\hline LR- & 0.42 & $0.23-0.76$ & 0.39 & $0.22-0.71$ \\
\hline LR & 5.43 & $2.14-13.77$ & 6.70 & $2.62-17.15$ \\
\hline Kappa & 0.317 & $0.152-0.481$ & 0.365 & $0.197-0.534$ \\
\hline & & EF $\leq 51.0 \%$ & & Regression $\geq 0.135$ \\
\hline Sensitivity & $71.4 \%$ & $51.3 \%-86.8 \%$ & $96.4 \%$ & $81.7 \%-99.9 \%$ \\
\hline Specificity & $62.0 \%$ & $51.2 \%-71.9 \%$ & $66.3 \%$ & $55.7 \%-75.8 \%$ \\
\hline DA & $64.2 \%$ & $54.9 \%-72.7 \%$ & $73.3 \%$ & $64.5 \%-81.0 \%$ \\
\hline Youden's index & $33.4 \%$ & $13.9 \%-52.8 \%$ & $62.7 \%$ & $50.9 \%-74.6 \%$ \\
\hline PPV & $36.4 \%$ & $23.8 \%-50.4 \%$ & $46.6 \%$ & $33.3 \%-60.1 \%$ \\
\hline NPV & $87.7 \%$ & $77.2 \%-94.5 \%$ & $98.4 \%$ & $91.3 \%-100.0 \%$ \\
\hline LR+ & 1.88 & $1.32-2.67$ & 2.86 & $2.13-3.85$ \\
\hline LR- & 0.46 & $0.25-0.85$ & 0.05 & $0.01-0.37$ \\
\hline LR & 4.07 & $1.62-10.23$ & 53.13 & $6.89-409.50$ \\
\hline Kappa & 0.250 & $0.094-0.406$ & 0.457 & $0.318-0.596$ \\
\hline
\end{tabular}

Table 10:-Diagnostic characteristics of GRACE, time from fibrinolysis, EF and regression probability in prediction of complications

\begin{tabular}{|c|c|c|c|c|}
\hline Characters & Value & 95\% CI & Value & 95\% CI \\
\hline & \multicolumn{2}{|c|}{ GRACE $\geq 127.0$} & \multicolumn{2}{|c|}{ Time $\geq 9.0$} \\
\hline Sensitivity & $68.8 \%$ & $41.3 \%-89.0 \%$ & $81.3 \%$ & $54.4 \%-96.0 \%$ \\
\hline Specificity & $63.5 \%$ & $53.4 \%-72.7 \%$ & $69.2 \%$ & $59.4 \%-77.9 \%$ \\
\hline DA & $64.2 \%$ & $54.9 \%-72.7 \%$ & $70.8 \%$ & $61.8 \%-78.8 \%$ \\
\hline Youden's index & $32.2 \%$ & $7.7 \%-56.7 \%$ & $50.5 \%$ & $29.4 \%-71.6 \%$ \\
\hline PPV & $22.4 \%$ & $11.8 \%-36.6 \%$ & $28.9 \%$ & $16.4 \%-44.3 \%$ \\
\hline NPV & $93.0 \%$ & $84.3 \%-97.7 \%$ & $96.0 \%$ & $88.8 \%-99.2 \%$ \\
\hline LR+ & 1.88 & $1.24-2.85$ & 2.64 & $1.82-3.83$ \\
\hline LR- & 0.49 & $0.23-1.03$ & 0.27 & $0.10-0.76$ \\
\hline LR & 3.82 & $1.23-11.83$ & 9.75 & $2.60-36.59$ \\
\hline \multirow[t]{2}{*}{ Kappa } & 0.172 & $0.027-0.317$ & 0.286 & $0.130-0.441$ \\
\hline & \multicolumn{2}{|c|}{ Regression $\leq \mathbf{0 . 1 3 5}$} & & \\
\hline Sensitivity & $81.3 \%$ & $54.4 \%-96.0 \%$ & & \\
\hline Specificity & $73.1 \%$ & $63.5 \%-81.3 \%$ & & \\
\hline DA & $74.2 \%$ & $65.4 \%-81.7 \%$ & & \\
\hline Youden's index & $54.3 \%$ & $33.4 \%-75.3 \%$ & & \\
\hline$\underline{P P V}$ & $31.7 \%$ & $18.1 \%-48.1 \%$ & & \\
\hline NPV & $96.2 \%$ & $89.3 \%-99.2 \%$ & & \\
\hline LRt & 3.02 & $2.03-4.48$ & & \\
\hline LR- & 0.26 & $0.09-0.72$ & & \\
\hline LR & 11.76 & $3.12-44.39$ & & \\
\hline Kappa & 0.327 & $0.162-0.492$ & & \\
\hline
\end{tabular}

Table 11:-Diagnostic characteristics of GRACE, time from fibrinolysis, EF and regression probability in prediction of HF 


\begin{tabular}{|c|c|c|c|c|}
\hline Characters & Value & $95 \% \mathrm{CI}$ & Value & $95 \% \mathrm{CI}$ \\
\hline & \multicolumn{2}{|c|}{ GRACE $\geq 116.0$} & \multicolumn{2}{|c|}{ Time $\geq \mathbf{1 3 . 0}$} \\
\hline Sensitivity & $72.7 \%$ & $39.0 \%-94.0 \%$ & $54.5 \%$ & $23.4 \%-83.3 \%$ \\
\hline Specificity & $57.8 \%$ & $48.0 \%-67.2 \%$ & $89.9 \%$ & $82.7 \%-94.9 \%$ \\
\hline DA & $59.2 \%$ & $49.8 \%-68.0 \%$ & $86.7 \%$ & $79.3 \%-92.2 \%$ \\
\hline Youden's index & $30.5 \%$ & $2.6 \%-58.4 \%$ & $44.5 \%$ & $14.5 \%-74.4 \%$ \\
\hline PPV & $14.8 \%$ & $6.6 \%-27.1 \%$ & $35.3 \%$ & $14.2 \%-61.7 \%$ \\
\hline NPV & $95.5 \%$ & $87.3 \%-99.1 \%$ & $95.1 \%$ & $89.0 \%-98.4 \%$ \\
\hline LR+ & 1.72 & $1.13-2.63$ & 5.40 & $2.48-11.77$ \\
\hline LR- & 0.47 & $0.18-1.26$ & 0.51 & $0.26-0.97$ \\
\hline LR & 3.65 & $0.92-14.52$ & 10.69 & $2.80-40.85$ \\
\hline \multirow[t]{2}{*}{ Kappa } & 0.111 & $-0.005-0.227$ & 0.357 & $0.111-0.603$ \\
\hline & \multicolumn{2}{|c|}{$E F \leq 51.0$} & \multicolumn{2}{|c|}{ Regression $\geq 0.109$} \\
\hline Sensitivity & $81.8 \%$ & $48.2 \%-97.7 \%$ & $81.8 \%$ & $48.2 \%-97.7 \%$ \\
\hline Specificity & $57.8 \%$ & $48.0 \%-67.2 \%$ & $81.7 \%$ & $73.1 \%-88.4 \%$ \\
\hline DA & $60.0 \%$ & $50.7 \%-68.8 \%$ & $81.7 \%$ & $73.6 \%-88.1 \%$ \\
\hline Youden's index & $39.6 \%$ & $15.0 \%-64.2 \%$ & $63.5 \%$ & $39.5 \%-87.4 \%$ \\
\hline PPV & $16.4 \%$ & $7.8 \%-28.8 \%$ & $31.0 \%$ & $15.3 \%-50.8 \%$ \\
\hline NPV & $96.9 \%$ & $89.3 \%-99.6 \%$ & $97.8 \%$ & $92.3 \%-99.7 \%$ \\
\hline LR+ & 1.94 & $1.36-2.76$ & 4.46 & $2.75-7.24$ \\
\hline LR- & 0.31 & $0.09-1.11$ & 0.22 & $0.06-0.78$ \\
\hline LR & 6.16 & $1.27-29.88$ & 20.03 & $4.01-99.89$ \\
\hline Kappa & 0.142 & $0.028-0.256$ & 0.366 & $0.171-0.561$ \\
\hline
\end{tabular}

Table 12:-Diagnostic characteristics of GRACE, time from fibrinolysis, EF and regression probability in prediction of HF

\section{Conclusion:-}

The long delay pharmacoinvasive strategy in intermediate to high GRACE score after successful fibrinolysis in non PCI-capable facilities were associated with worse cardiovascular outcomes (death, re hospitalized with ACS, rehospitalized with HF and stroke) than the patients with low GRACE score at short term follow up. The GRACE score, the time from fibrinolysis to PCI and regression probability were significant factors that predict complications, ACS and HF, while EF was a significant factor that predicts complications and HF.

\section{Recommendations:-}

1. GRACE risk score is helpful for guiding the clinicians in non PCI-capable centers to select those patients who need early intervention in STEMI patients after fibrinolytic therapy

2. Early transfer for early PCI after successful fibrinolysis to decrease the rate of ischemic complications after myocardial infarction.

3. High GRACE score is a very helpful predictor for poor cardiovascular outcomes in STEMI patients.

4. High GRACE score mandates early intervention in the pharmacoinvasive pathway.

5. A bigger scale study is recommended to set the cut off values of GRACE score in guiding early intervention in the pharmacoinvasive strategy.

\section{Limitations:-}

There are some limitations in our study that may compromise the clinical implication. The large number of excluded patients reflected the limited accessibility to coronary intervention within 2 weeks. The mortality was lower because the small number of patients with high GRACE risk were included in our study. The GRACE score modality which we are validating in this study is the one that enables us to estimate risk of death 6 months after discharge following an ACS episode but we follow our patients for 3 months only. The precise assessment of the duration and nature of cardiac arrest during hospital admission couldn't be achieved accurately. The results were obtained from only two center (Al-Azhar University hospital and El-Mtareya Teaching Hospital). 


\section{References:-}

1. Danchin N., Di Mario C. and Falk V. et al., (2014): Folliguet T, Garg S, Huber K,James S, Knuuti J, LopezSendon J, Marco J, Menicanti L, Ostojic M, PiepoliMF, Pirlet C, Pomar JL, Reifart N, Ribichini FL, Schalij MJ, Sergeant P, Serruys PW, Silber S, Uva MS, Taggart D. Guidelines on myocardial revascularization, Eur Heart J. 2014.

2. Srimahachota S., Boonyaratavej S. and Kanjanavanit R. et al., (2012): Thai Registry in Acute Coronary Syndrome (TRACS)-An Extension of Thai Acute Coronary Syndrome Registry (TACS) Group: Lower Inhospital but still high mortality at one-year. J Med Assoc Thai. 2012 .

3. The GRACE Investigators. Rationale and design of the GRACE (Global Registry of Acute Coronary Events) project: a multinational registry of patients hospitalized with acute coronary syndromes. Am Heart J. 2001.

4. Eagle K., Lim M. and Dabbous O. et al., (2004): GRACE Investigators, et al. A validated prediction model for all forms of acute coronary syndromes in an international registry. JAMA. 2004.

5. Thygesen, Alpert, Jaffe, et al., (2012): Third universal definition of myocardial infarction. Circulation, 7(4), 275-295.

6. Leung Y, Kaplan GG, Rioux KP, Hubbard J, Kamhawi S, et al. (2012) Assessment of variables associated with smoking cessation in Crohn's disease. Dig Dis Sci 57: 1026-1032

7. Catapano A, Graham I, De Backer G, Wiklund O, Chapman J, et al. (2016): 2016 ESC/EAS Guidelines for the Management of Dyslipidaemias. Eur Heart J 37: 2999-3058.

8. Mancia G, Fagard R, Narkiewicz K, Redon J, Zanchetti A, et al. (2013) 2013 ESH/ESC guidelines for the management of arterial hypertension: the Task Force for the Management of Arterial Hypertension of the European Society of Hypertension (ESH) and of the European Society of Cardiology (ESC). Eur Heart J 34: 2159-2219.

9. Vanderpump MPJ.(2005): The epidemiology of thyroid diseases. In: Braverman LE, Utiger RD, editors. Werner and Ingbar's The Thyroid: A Fundamental and Clinical Text. 9th edn. Philadelphia: JB LippincottRaven; 2005. p. 398-496.

10. Windecker S., Kolh P. and Alfonso F. et al., (2014): ESC/EACTS Guidelines on myocardial revascularization: The Task Force on Myocardial Revascularization of the European Society of Cardiology (ESC) and the European Association for Cardio-Thoracic Surgery (EACTS) Developed with the special contribution of the European Association of Percutaneous Cardiovascular Interventions (EAPCI). Eur Heart J. 2014;35(37):2541619.

11. D’Souza SP., Mamas MA. and Fraser DG. et al., (2011): Routine early coronary angioplasty vs. ischaemiaguided angioplasty after thrombolysis in acute ST elevation myocardial infarction: a meta-analysis. Eur Heart J. 2011;32(8):972-8.

12. Eagle KA., Lim MJ. and Dabbous OH. et al., (2004): A validatedprediction model for all forms of acute coronary syndromes in aninternational registry. JAMA. 2004.

13. 4- Ascenzo FD., Biondi-Zoccai G. and Moretti C. et al., (2012): TIMI, GRACE and alternative risk scores in acute coronary syndromes: a metaanalysis of 40 derivation studies on 216,552 patients and of 42 validation studies on 31,625 patients. Contemp Clin Trials. 2012;33:507

14. . Scheller B., Hennen B. and Hammer B. et al., (2003): SIAM III Study Group. Beneficial effects of immediate stenting after thrombolysis in acute myocardial infarction. J Am Coll Cardiol. 2003;42:634-41.

15. Cantor W., Fitchett D. and Borgundvaag B. et al., (2009): TRANSFER-AMI Trial Investigators. Routine early angioplasty after fibrinolysis for acute myocardial infarction. N Engl J Med. 2009;360:2705-18.

16. Bohmer E., Hoffmann P. and Abdelnoor M. et al., (2010): Efficacy and safety of immediate angioplasty versus ischemia-guided management after thrombolysis in acute myocardial infarction in areas with very long transfer distances results of the NORDISTEMI (NORwegian study on DIstrict treatment of ST-elevation myocardial infarction). J Am Coll Cardiol. 2010;55:102-10.

17. Di Mario C., Dudek D. and Piscione F. et al., (2008): CARESS-in-AMI (Combined Abciximab RE-teplase Stent Study in Acute Myocardial Infarction) Investigators. Immediate angioplasty versus standard therapy with rescue angioplasty after thrombolysis in the combined Abciximab REteplase Stent Study in Acute Myocardial Infarction (CARESS-in-AMI: an open, prospective, randomised, multicentre trial. Lancet. 2008;371:559-68. 